\title{
A Prototype Plant for Oilseed Extraction: Analysis of Mass and Energy Flows
}

\author{
Ramoon B. L. Temporim ${ }^{1, * \mathbb{C}}$, Alessandro Petrozzi ${ }^{1}$, Valentina Coccia ${ }^{2}$, Franco Cotana ${ }^{2}$ \\ and Gianluca Cavalaglio ${ }^{2}$ (D) \\ 1 CIRIAF-Interuniversity Research Center on Pollution and Environment "Mauro Felli", \\ Via G. Duranti, 67-06125 Perugia, Italy; petrozzi@crbnet.it \\ 2 Department of Engineering, UNIPG-University of Perugia, Via G. Duranti, 93-06125 Perugia, Italy; \\ coccia@crbnet.it (V.C.); cotana@crbnet.it (F.C.); cavalaglio@crbnet.it (G.C.) \\ * Correspondence: barroslovate@crbnet.it; Tel.: +39-075-5853574
}

Received: 5 October 2020; Accepted: 20 November 2020; Published: 23 November 2020

\begin{abstract}
The focus of this study is to analyze the energy flows related to cardoon oil processing based on the estimated electricity consumption. It was carried out in a prototype oilseed extraction plant located in Umbria Region, Italy. This installation consists of the following processes: seed weight-storage, transportation, sifting, milling, filtering, and oil storage. Approximately 49,000 kg dry basis (DB) of cardoon seeds (Cynara cardunculus) were processed. Cardoon seeds were chosen as a feedstock due to their sustainability characteristics. Before processing, samples of raw material were analyzed in terms of moisture, oil content, impurity, density, and lower heating value. The input-output flows were measured in terms of weight and energy consumption. Its data were used to perform the mass-energy balance and estimate the efficiency of processes. About $8505 \mathrm{~kg}$ of filtered oil was obtained from raw material. The efficiency of the process chain was $84.42 \%$ concerning the oil content in the seeds. For the same period, the plant required a total of 17,556 MJ of electric energy from the grid for its operation. 321,507 MJ were obtained from oil and 688,875 MJ from oilcake. About $5.48 \%$ of the energy produced by oil extraction was virtually used in the process.
\end{abstract}

Keywords: cardoon; Cynara cardunculus; seeds oil; oilcake; energy balance; mass balance; oil extraction

\section{Introduction}

In the current scenario of population growth, declining biodiversity, and increasing climate change, the importance of studying and implementing the use of alternative energy sources with a high level of sustainability has grown. In this circumstance, bioenergy from energy crops has gained attention, and great emphasis has been given to the use of biomass as an alternative source for energy production [1].

However, with the growing use of arable land for energy crop production, concerns began to emerge. Competition in the use of these lands for energy production, competing with the spaces used to produce human food, animal food, and fiber production [2], could reduce the supply of food and raise their prices. [3].

With regard to that, the energy production from non-food crops and residual biomass emerges as an interesting option to save resources and protect the environment, becoming one of the largest fields of research to produce biofuels and biochemicals [4].

In this respect, stands the cultivation of Cynara cardunculus due to its interesting sustainability characteristics, confirmed by several studies in the last 30 years. In fact, Gominho et al. [5] confirm that this species represents a productive crop capable of growing in Mediterranean regions with strict 
edaphoclimatic conditions [6]. In addition, the development cycle of Cynara cardunculus in other climate conditions has been described by various authors [7-11].

Through a low level of management, Cynara cardunculus performs as a hardy crop, presenting characteristics such as perennial life form, annual growing cycle, vigorous regrowth, bee-attractive flowers, and adaptation to drought stress $[12,13]$. That makes this plant an excellent candidate to be grown as a perennial field crop for multi-purposes uses [1,5].

Different works address the use of Cynara cardunculus biomass for several purposes, as the use to produce liquid and solid biofuels [14,15], biogas, bioplastics [4], bio-oil (pyrolysis), and to perform gasification [16].

The whole biomass of cardoon is basically composed of two fractions, lignocellulosic material, which is the highest percentage in terms of mass (90-92\%), and seeds (8-10\%), These seeds, even presenting a reduced percentage, are the fraction of greater added value given its oil content [5]. These seeds can have an oil content of 20-32\% [17].

The process of extracting oil from oilseeds is possible through a variety of chemical and mechanical techniques [18]. Solvent extraction is the most efficient method. However, the use of solvents has high operating costs, a large burden of environmental impacts, in addition to complex processing steps. On the other hand, the advantages of mechanical extraction include simplification of the process chain, presents the lower burden of environmental impacts, good quality oil, in addition to the possibility of using its oilcake for other purposes, as long as it is not contaminated by solvents [19-21].

In mechanical extraction, essentially, the seeds are placed between barriers and compressed, forcing the oil out of the seeds [22,23]. The most common methods for mechanical extractions are the use of hydraulic or screw presses. In particular, the advantages of the screw press are its better performance compared to the hydraulic press, in addition to the possibility of being adapted for continuous processing $[24,25]$.

Given this background, the goal of this work is to investigate the mass and energy flows of the mechanical oil extraction process from Cynara cardunculus seeds. Accordingly, the experiment was carried out in an oil extraction prototype plant where mass flows were measured, and electricity consumption was estimated based on operating times.

Therefore, this work presents an overview of the process chain used for oil extraction, starting from the receipt of the seeds until the stage of obtaining oil. The layout of the extraction prototype and its analysis of mass-energy flows are presented. Additionally, the yields are presented and analyzed in order to measure the effectiveness of the method used. Finally, this work's progression prospects and the possible uses of oil as a raw material for other products are described.

The prototype plant is in Rocca di Sant'Apollinare, Municipality of Marsciano, Province of Perugia, Umbria Region, Italy. The experimental structure was dimensioned by the Biomass Research Center (CRB) and the Interuniversity Research Center on Pollution and the Environment "Mauro Felli" (CIRIAF), financially supported by the Italian Ministry of Agriculture. This structure was revitalized using high sustainability criteria and architectural integration to insert the renewable energy production system and preserve its historical heritage.

\section{Materials and Methods}

\subsection{Description and Characterization of the Raw Material (Cynara cardunculus)}

The raw material used was cardoon seeds (Cynara cardunculus) due to its sustainable characteristics. This plant is a high-efficiency energy crop that can be grown on marginal lands and polluted soils without significant investments in agricultural maintenance $[5,26]$.

This species develops in areas considered with low edaphoclimatic characteristics and absence of irrigation. These characteristics make this crop highly efficient in terms of energy demand and reduction of pollutant emissions. 
The cardoon seeds were supplied by Novamont S.p.A. through an agreement with CIRIAF to study the optimization of the oilseed extraction process in the prototype plant. This raw material was grown in marginal lands located in Porto Torres, Sardinia, Italy.

The crop management was carried out employing as minimum as possible chemical fertilizers, favoring the use of compost materials to nurture the crop. The cultivation was carried out without using any irrigation method and defensives application. The adoptions favored reducing the minimum possible load of environmental impacts in the phase of agricultural production.

The supplied raw material was characterized in the University of Perugia, Biomass Research Canter's laboratories in terms of moisture, impurities, and oil content, essential characteristics to determine the yields and efficiency of the process. A moisture analyzer (model Mettler Toledo HB43-S) was implemented to measure the raw material's moisture content [27]. Impurities were determined by manual selection. The oil content in the seeds was determined based on National Renewable Energy Laboratory National's procedure, Determination of Extractives in Biomass [28].

\subsection{Layout and Operations of the S'Apollinare's Oil Extraction Plant}

The oil extraction plant prototype is integrated into the Rocca di Sant'Apollinare. This structure is a fortress that was restored according to the energy efficiency and sustainability criteria in order to reach the circular economy proposals. In this regard, the structure was designed to be energetically self-sufficient by using a cogeneration engine fed with vegetable oil produced by the plant.

The structures and machinery of the extraction plant are shown in Figure 1.

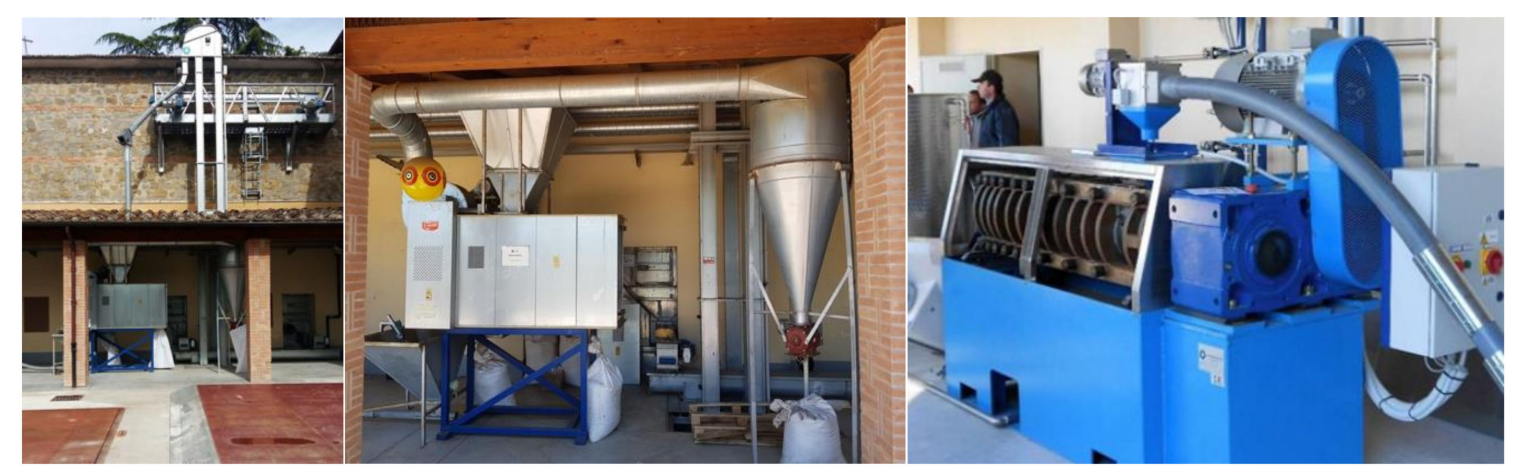

Figure 1. The seed storage, transportation, and sifting set (left); sieve (center); milling machine (right).

The process chain required for oil extraction is organized according to the flowchart shown in Figure 2.

According to Figure 2, the first stage is the transport and storage of the raw material. The seeds arrive by truck weighed in the weighbridge before unloading in a hopper with $2 \mathrm{~m}^{3}$ capacity. From the hopper, these seeds are moved by a conveyor system composed of belts and a bucket elevator toward the silos with a $180 \mathrm{~m}^{3}$ capacity. During storage, the grains undergo a drying process by using forced air passage in a fluidized bed.

Next, in the selection set, seeds were extracted from the silos by the belt and bucket elevator system for the cleaning process. The system consisted of three levels of sieving, composed of a coarse sieve mesh size 7-8 $\mathrm{mm}$, a fluidized bed to remove the lightest impurities such as bark and leaves through a blowing air process, and a final sieve mesh size $3 \mathrm{~mm}$. These residues were then transported to a container.

Then, in the extraction set, sifted seeds were transported through a screw conveyor to the screw mill, where a continuous process extracted the oil. This milling system works with the seeds' compression between an internal chamber, forcing by a squeezing screw, rotating internally on its longitudinal axis. The raw oil (rich in suspended solids) flows out through some apertures in the cylindrical chamber, 
being stored temporarily in a container below the mill. The oilcake was tangentially expelled at the cylinder extremity and transported through a screw conveyor into a container.

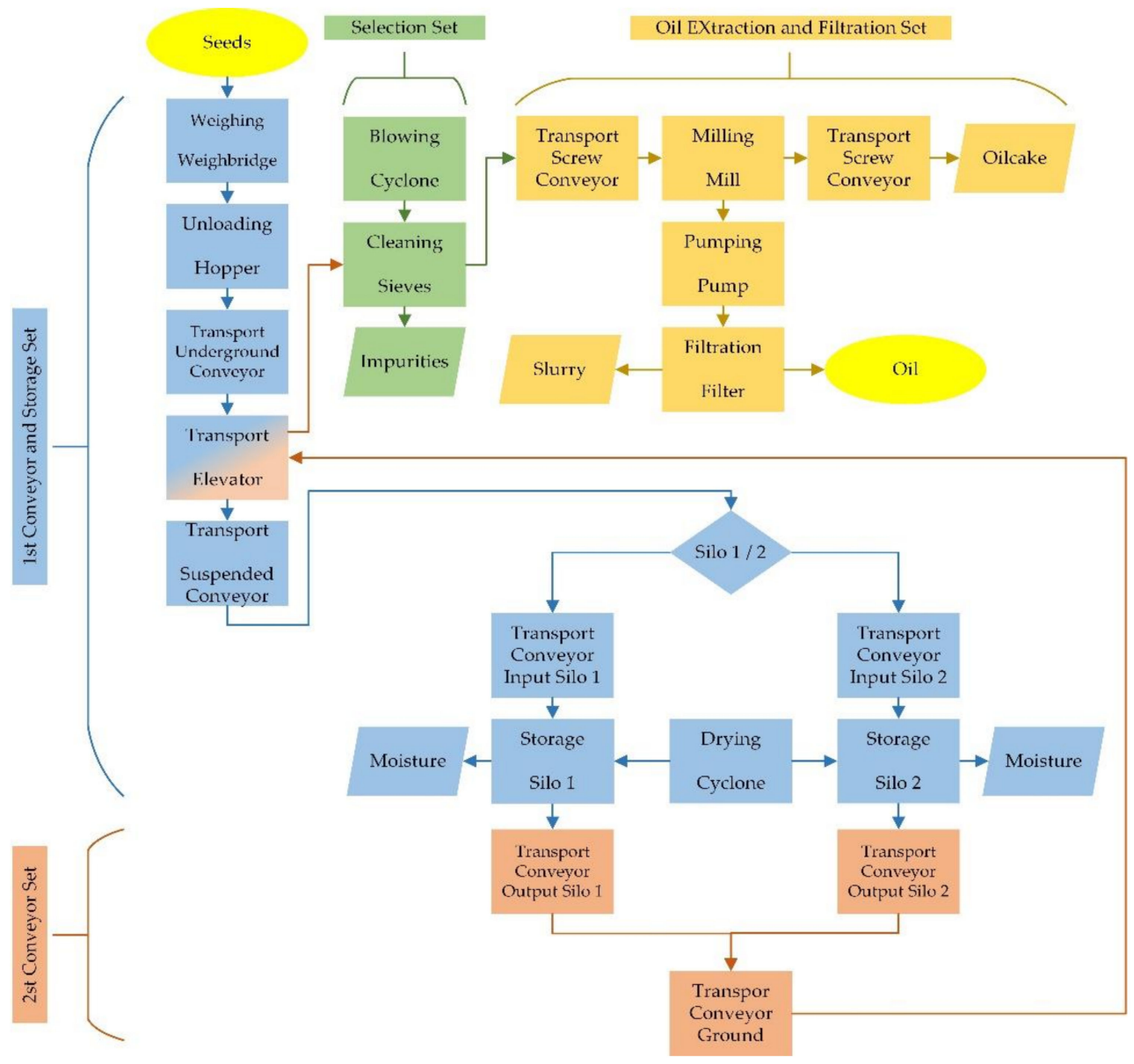

Figure 2. Process flowchart.

The raw oil is pumped through a set of filters, separating the rich-oilcake and the oil. The filtered oil is pumped into the storage tanks with $100 \mathrm{~m}^{3}$, and the slurry (or rich oilcake) in a container.

At the end of the chain, there is a combined heat and power engine (CHP engine) of $100 \mathrm{~kW}$ of electrical energy and $135 \mathrm{~kW}$ of thermal energy recovered from engine oil and smoke through heat exchangers. From $135 \mathrm{~kW}$ of recovered energy, $75 \mathrm{~kW}$ are provided for cooling employing an absorption chiller, and $60 \mathrm{~kW}$ of heat power. The engine's hourly consumption is about $25 \mathrm{~L}$ of oil.

The machinery has a cycle that accompanies the worker's shift $(8 \mathrm{~h})$. In the final phase of daily operation, the loading screw and the mill are fed with sunflower seeds for about $10 \mathrm{~min}$ to clean the machines.

All the necessary power required for the machinery is supplied by a set of fourteen electric engines, thirteen engines up to $3 \mathrm{~kW}$, and one engine of $22 \mathrm{~kW}$ used in the milling process.

Regarding the processes carried out by each piece of equipment, they work automatically according to a time regime. On the first working day, only the engines responsible for unloading the truck and transporting the biomass to the silos operate at maximum power ("1st Conveyor and Storage Set"). The entire plant is activated from the second working day and operates according to the following time regime. After a 2-min interval from the plant's activation, the "2nd Conveyor Set" is deactivated as soon as the sieve system's reservoir is filled. After a 15-min interval from the plant's activation, the "Selection Set" is automatically deactivated once it has filled the seed reservoir that feeds the mechanical press. The "Oil Extraction and Filtration Set" works continuously. After all the previous 
phases are deactivated, "Oil Extraction and Filtration Set" continues for another $15 \mathrm{~min}$. Within $30 \mathrm{~min}$ of operation, the regime is restarted.

\subsection{Monitoring and Sampling of the Processes}

During the campaign, the machinery operating time was monitored and recorded by the operator. Moreover, representative samples were taken at all stages of the process chain and were analyzed at the University of Perugia, Biomass Research Canter's laboratories. Sifted residues, sifted seeds, oil, and oil cake were sampled. All these samples were analyzed, according to the necessity, in terms of moisture, oil content, and Low Heat Value (LHV). These are essential parameters for the determination of mass and energy flows, in addition to the analysis of process efficiency.

The methods used to determine the moisture and oil content were the same as reported in Section 2.1. The LHV was determined using a calorimeter (model LECO AC-350) [29].

\subsection{Energy Flows, Yields, and Efficiency of the Oil Extraction}

To determine the plant's energy flows, an estimate of the machinery's consumption was made. Based on the time regime and the monitoring, it was possible to estimate the electrical consumption of the plant.

According to the amount of oil produced and the total quantities of raw material and selected seeds that were processed, it was possible to determine the oil yields.

Based on the characterization of the seeds, in which it was possible to calculate the total oil content and the effective amount of oil extracted from the seeds, it was possible to determine the process's efficiency.

The total energy contained in the final products, oil, and oilcake, were also calculated based on the LHV measures. Moreover, the energy consumption rate per $\mathrm{kg}$ of processed seeds was calculated, in addition to the energy production rate obtained from oil.

\section{Results}

The investigation was carried out from 2 May to 15 June. During this period, Novamont S.p.A supplied 50,421.76 kg wet basis (WB) of pre-selected raw material that was processed.

\subsection{Raw Material (Cynara cardunculus)}

The raw material was analyzed in terms of moisture, impurities, and oil content, as described in Section 2.1. The results are reported in Table 1.

Table 1. Characterization of the raw material.

\begin{tabular}{cc}
\hline Amount & $\mathbf{5 0 , 4 2 1 . 7 6 ~ k g ~ W B}$ \\
\hline Moisture & $2.39 \%$ \\
Impurities & $7.00 \%$ \\
Oil content (seeds) & $20.64 \%$ \\
\hline
\end{tabular}

Before processing, the raw material presented, based on its characterization, an average of $2.39 \%$ of moisture, total impurities of $7 \%$, and seeds presented a total of $20.64 \%$ of oil content.

\subsection{Mass Flows}

During the experimentation, 49,216.68 kg DB of raw material were received and processed, as shown in Figure 3.

In order to obtain detailed mass flow, all processes were monitored. After cleaning the raw material, it was possible to obtain a total of $48,823.84 \mathrm{~kg}$ DB of selected seeds, from which $387.96 \mathrm{~kg}$ DB of impurities were removed. After the milling process, $9107.63 \mathrm{~kg}$ of raw oil was obtained, which was 
filtered, obtaining $8505.48 \mathrm{~kg}$ of filtered oil and $600.15 \mathrm{~kg}$ of slurry. As a by-product, $39,406.76 \mathrm{~kg}$ DB of oilcake was produced.

Regarding the mass losses, the calculations showed that $316.33 \mathrm{~kg}$ DB were lost during the processes, corresponding to less than $1 \%$ in relation to the raw material DB.

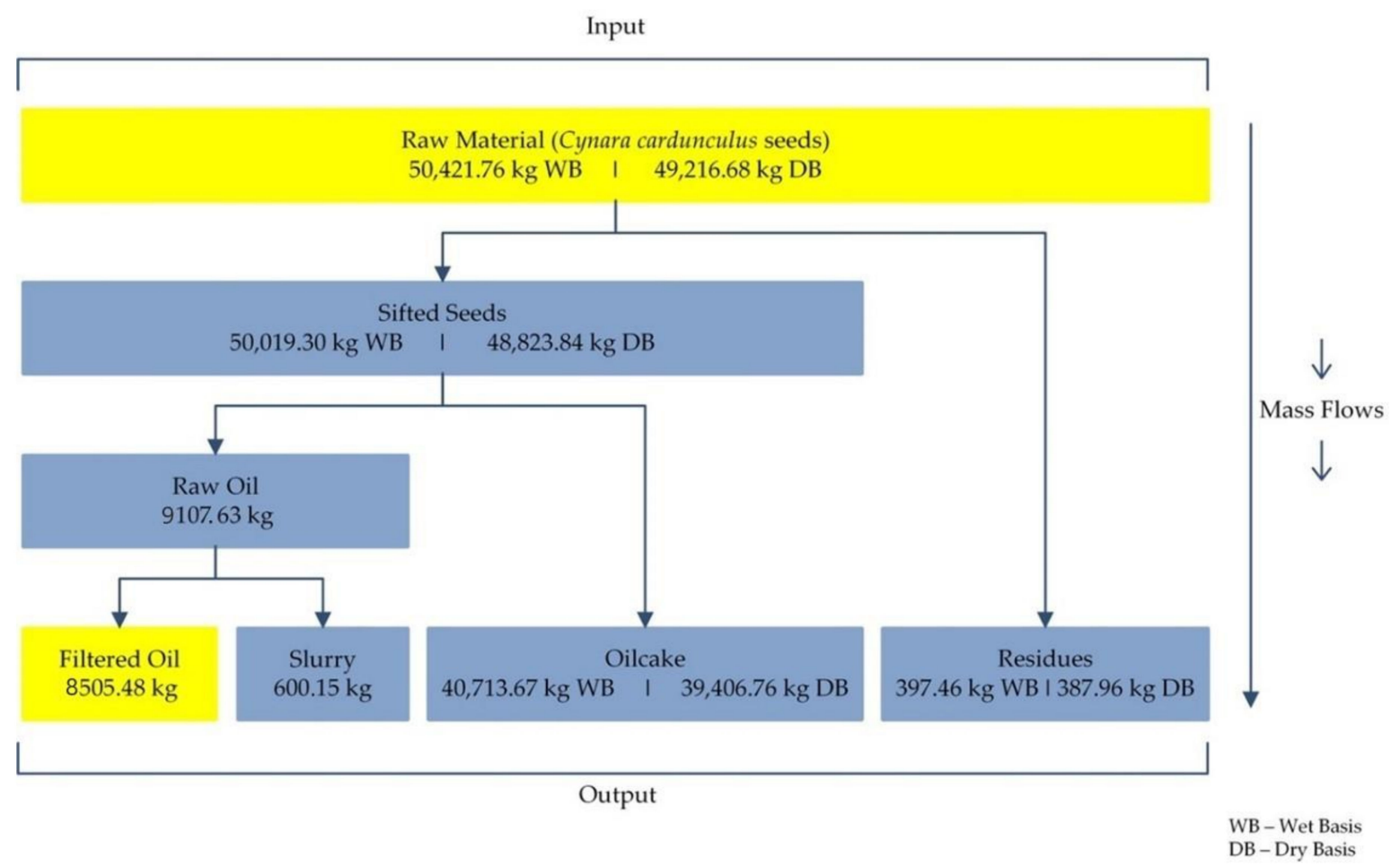

Figure 3. Mass balance chart.

\subsection{Samples Characterization}

As specified in Section 2.3, during seed processing, sampling of sifted seeds, sifted residues, oil, and oilcake were taken. These samples were characterized in terms of moisture, oil content, and LHV. The results are shown in Table 2.

Table 2. Characterization of the samples.

\begin{tabular}{ccccc}
\hline Sample & Seeds & Residues & Oil & Oilcake \\
\hline Moisture $(\%)$ & 2.39 & 2.39 & - & 3.21 \\
Oil content $(\%)$ & 20.64 & - & 100 & 5.11 \\
LHV $(\mathrm{MJ} / \mathrm{kg})$ & - & - & 37.80 & 16.92 \\
\hline
\end{tabular}

As shown in Table 2, the selected seeds' characterization showed average moisture of $2.39 \%$ and oil content of $20.64 \%$. The residues showed the same percentage of moisture as the seeds. In terms of the oil, it presented a LHV of $37.80 \mathrm{MJ} / \mathrm{kg}$. After characterization, the oilcake presented moisture of $3.21 \%$, oil content of $5.11 \%$, and LHV of $16.92 \mathrm{MJ} / \mathrm{kg}$.

\subsection{Energy Flows}

The electrical energy demand was estimated based on each machine's operation time and power, as reported in Table 3.

All engines up to $3 \mathrm{~kW}$ operated at the maximum available power and the engine dedicated to the mill were configured to operate at half of its power, $11 \mathrm{~kW}$. 
For the whole period of operation, 17,555.62 MJ of electrical energy was consumed by the engines. About $8.11 \%$ of the energy consumed was demanded by the transport system composed of belts and bucket elevators. The cleaning process, composed of the sieve system and a cyclone, was responsible for $6.52 \%$ of the electrical energy consumed. The highest percentage of consumption was demanded by the extraction process of the oil composed by the mill, screw conveyors, and pumps. This process absorbed $85.37 \%$ of the energy consumed by the plant.

Table 3. Energy demands.

\begin{tabular}{|c|c|c|c|c|c|c|}
\hline Stage/Set & $\begin{array}{l}\text { Equipment } \\
\text { (Engine) }\end{array}$ & $\begin{array}{c}\text { Engine } \\
\text { Power }(k W)\end{array}$ & $\begin{array}{l}\text { Total Power } \\
\text { (kW) }\end{array}$ & $\begin{array}{c}\text { Total } \\
\text { Operating (h) }\end{array}$ & $\begin{array}{c}\text { Energy } \\
\text { Demand (MJ) }\end{array}$ & $\begin{array}{c}\text { Energy } \\
\text { Demand (\%) }\end{array}$ \\
\hline \multirow{4}{*}{$\begin{array}{l}\text { 1st Conveyor } \\
\text { and Storage }\end{array}$} & $\begin{array}{l}\text { belts } \\
\text { (underground) }\end{array}$ & 3 & \multirow{4}{*}{12} & \multirow{4}{*}{18.83} & \multirow{4}{*}{813.60} & \multirow{4}{*}{$4.63 \%$} \\
\hline & elevator (up) & 3 & & & & \\
\hline & Belts & 3 & & & & \\
\hline & belts (input silos) & 3 & & & & \\
\hline \multirow{3}{*}{$\begin{array}{l}\text { 2nd } \\
\text { Conveyor }\end{array}$} & belts (output silos) & 3 & \multirow{3}{*}{9} & \multirow{3}{*}{18.83} & \multirow{3}{*}{610.20} & \multirow{3}{*}{$3.48 \%$} \\
\hline & belts (ground) & 3 & & & & \\
\hline & elevator & 3 & & & & \\
\hline \multirow{2}{*}{ Cleaning } & sieve & 1.50 & \multirow{2}{*}{2.25} & \multirow{2}{*}{141.25} & \multirow{2}{*}{1144.12} & \multirow{2}{*}{$6.52 \%$} \\
\hline & cyclone & 0.75 & & & & \\
\hline \multirow{4}{*}{$\begin{array}{l}\text { Oil } \\
\text { Extraction }\end{array}$} & $\begin{array}{l}\text { screw input } \\
\text { (seeds) }\end{array}$ & 1.10 & \multirow{4}{*}{14.70} & \multirow{4}{*}{282.50} & \multirow{4}{*}{$14,949.90$} & \multirow{4}{*}{$85.16 \%$} \\
\hline & mill & 11 & & & & \\
\hline & screw output & 1.50 & & & & \\
\hline & pump output & 1.10 & & & & \\
\hline Filtration & pump filter & 0.75 & 0.75 & 14 & 37.80 & $0.21 \%$ \\
\hline Total & - & - & - & - & $17,555.62$ & $100 \%$ \\
\hline
\end{tabular}

\subsection{Yields and Efficiency}

By monitoring processes, it was possible to calculate the yields and efficiency of oil extraction, as shown in Table 4.

Table 4. Yields and efficiency.

\begin{tabular}{cccc}
\hline & & Wet Basis & Dry Basis \\
\hline Yields & Filtered oil/Raw material & $16.87 \%$ & $17.28 \%$ \\
& Filtered oil/Sifted seeds & $17.00 \%$ & $17.42 \%$ \\
\hline Efficiency & Filtered oil/Oil content & - & $84.42 \%$ \\
\hline
\end{tabular}

Considering the wet basis, the yield of oil from raw material and sifted seeds were respectively, $16.87 \%$ and $17.00 \%$. Concerning the dry basis, the yield of oil from the raw material and sifted seeds were respectively, $17.28 \%$ and $17.42 \%$.

During the experiment, $8505.48 \mathrm{~kg}$ of filtered oil was obtained from the $10,075.37 \mathrm{~kg}$ of oil contained in the seeds. Therefore, the efficiency of the process was $84.42 \%$.

Regard the energy content obtained with the products, from $8505.48 \mathrm{~kg}$ of filtered oil, with a LHV of $37.80 \mathrm{MJ} / \mathrm{kg}$, were obtained 321,507.14 MJ of energy. As for the oilcake, with 40,713.67 kg and LHV of $16.92 \mathrm{MJ} / \mathrm{kg}$, were obtained 6,888,675.30 MJ of energy.

The energy consumption rate per $\mathrm{kg}$ of seeds and oil produced was $0.36 \mathrm{MJ} / \mathrm{kg}$ of seeds and $2.06 \mathrm{MJ} / \mathrm{kg}$ of oil. Moreover, the rate of energy production per MJ of electricity consumed was $65.93 \mathrm{MJ} / \mathrm{MJ}$. 


\section{Discussion}

The raw material's characterization presented an oil content percentage of $20.64 \%$, which is in accordance with values already referenced in other studies $[5,17,30]$.

In the processing phase that lasted between 2 May to 15 June, from 49,216.68 $\mathrm{kg}$ DB of raw material, with approximately $7.00 \%$ impurities, $387 \mathrm{~kg}$ of residues were removed, which represented a removal of approximately $1 \%$ of the total initial mass value. In this sense, there is a process that should be optimized. The cleaning of the sieves should be carried out more frequently to have greater efficiency.

In relation to losses during processing, as reported in session 3.2, approximately $316.33 \mathrm{~kg}$ of material was lost during processing. This equated to less than $1 \%$ of the total raw material. When compared to previous work carried out at the same oil processing plant, as reported by Cavalaglio et al. [15], where losses were approximately $5 \%$, it can be seen there were improvements at the time of processing since the process was monitored several times. In the processes where there were losses, the mass flows were resized, for instance, at transportation between processes.

The mass flow was set to $357 \mathrm{~kg}$ per hour, getting a flow of $144 \mathrm{~kg}$ per hour of oilcake and $32 \mathrm{~kg}$ per hour of oil. With this mass flow regimes, the engine could operate at the power of $11 \mathrm{~kW}$. In this configuration, due to the compression and friction of the seeds with the chamber's internal walls, the temperature of seeds reached a maximum of $101^{\circ} \mathrm{C}$, the ideal temperature for extracting cardoon oil [15]. In addition, this mass flow regime was established, taking into account the possible use of the $\mathrm{CHP}$ engine, which has an average consumption of $25 \mathrm{~L}$ per hour. Therefore, with this mass flow, it would be possible to provide adequate amounts of oil for engine operation and oil accumulation for other uses.

Concerning the oil's characterization, it presented the calorific value of $37.80 \mathrm{MJ} / \mathrm{kg}$, a value already reported according to previous work carried out with cardoon [15] and the LHV average of other vegetable oils [31]. The by-product, oilcake, presented a lower LHV regard oil, $16.92 \mathrm{MJ} / \mathrm{kg}$, since its lower oil content.

About the efficiency of the process, as verified by the bibliographies where the comparison between traditional extraction methods was performed, the mechanical extraction method presented a lower average of efficiency when compared to the process with solvents. In the present study, the process efficiency of $84.42 \%$ was lower compared to the efficiency of a potential solvent extraction process that can range from 90-98\% efficiency, according to Nde et al. [23]. However, there are advantages to the use of the mechanical method. In the oilcake remained approximately $6 \%$ of oil, which cannot be extracted by the mechanical extraction process. This oil that remains in the by-product gives it greater added value when used for animal feed, given its god nutritional value. In fact, according to Genovese et al. [32], the chemical-nutritive characteristics of the oilcake, which are amino acids and fatty acids, provide its high potential as animal feed.

\section{Conclusions}

The objective of this work was to investigate the mass and energy flows of the mechanical oil extraction process from cardoon (Cynara cardunculus) seeds in a prototype plant located at Rocca di Sant'Apollinare, Municipality of Marsciano, Province of Perugia, Umbria Region, Italy.

The prototype plant was equipped with all the necessary stages for processing the seeds and obtaining the oil. The process chain was composed of the phases of transport and storage in silos, cleaning of the raw material through a multi-sieve system, extraction of oil through a mechanical process (screw press), filtration, and oil and oilcake storage. All the power demanded by the plant was provided by a set of thirteen electric engines, operating with powers ranging from $0.75 \mathrm{~kW}$ to $11 \mathrm{~kW}$.

During the processing phase, essential parameters were monitored and recorded, such as operating time and mass flows. All mass fractions such as raw material, sifted seeds, residues, raw oil, oilcake, filtered oil, and slurry were sampled and analyzed in the laboratory. When necessary, these samples were characterized in terms of impurities, moisture, oil content, and LHV. These parameters were used 
to determine the mass and energy flows, in addition to analyzing the yield and efficiency of the oil extraction process.

In this experiment, $49,216.68 \mathrm{~kg}$ DB of raw material containing $20.64 \%$ of oil was processed in $282.50 \mathrm{~h}$. A total of $8505.48 \mathrm{~kg}$ of oil with LHV of $37.80 \mathrm{MJ} / \mathrm{kg}$ were obtained; $39,406.76 \mathrm{~kg}$ DB of oilcake with LHV of $16.92 \mathrm{MJ} / \mathrm{kg}$; in addition to $600.15 \mathrm{~kg}$ of slurry and $387.96 \mathrm{~kg}$ DB of residues. Approximately $316.33 \mathrm{~kg}$ DB of mass was lost, less than $1 \%$ of the raw material's total weight.

Energy flows were estimated based on engine operating time and its power. A total of 17,555.62 MJ of electrical energy were consumed in the $282.50 \mathrm{~h}$ of operation. Approximately $85.37 \%$ of the energy demanded was consumed by the extraction process.

Finally, the yields of filtered oil from raw material DB and sifted seeds DB were respectively, $17.28 \%$ and $17.42 \%$. The efficiency of the extraction was $84.42 \%$. The energy consumption rates were $0.36 \mathrm{MJ} / \mathrm{kg}$ of seeds and $2.06 \mathrm{MJ} / \mathrm{kg}$ of oil. Furthermore, the rate of energy production per MJ of electricity consumed was $65.93 \mathrm{MJ} / \mathrm{MJ}$.

\section{Perspectives of the Project}

The future perspective of this work will be using the data obtained during the experiment to develop the Life Cycle Assessment in order to understand the environmental impacts caused by this activity and to understand the best application of oil in terms of the impacts related to its final application. For this purpose, the boundaries of the analyzed system will be expanded upstream and downstream of the oil extraction plant.

Preliminarily, the frontiers of analysis will be expanded upstream of the system, including the processes of agricultural cultivation and their respective contribution to carbon sequestration during the cardoon's plant development and the potential to reduce virtually the amount of $\mathrm{CO}_{2 \mathrm{eq}}$ emitted.

In a second step, it is intended to extend the boundaries of the system downstream of the extraction plant, considering some perspectives for oil use. It will be considered and analyzed using oil as a raw material for three different final products. In the first case, the use of oil for biodiesel production through the transesterification process. As a second possibility, the use of oil for bioplastic production was considered, as well as its use for energy production employing the CHP engine. In using the LCA technique, all possible perspectives will be analyzed, including a combination of these, aiming to find the most sustainable use of cardoon oil.

Author Contributions: Conceptualization, G.C., F.C. and A.P.; laboratory analysis R.B.L.T.; design of the study, G.C., A.P., V.C. and R.B.L.T.; writing-Original draft preparation, R.B.L.T., supervision of the research, G.C. and F.C. All authors have read and agreed to the published version of the manuscript.

Funding: This research received no external funding.

Acknowledgments: The authors acknowledge in particular the Fondazione Cassa di Risparmio di Perugia for the economic support in the context of the project "I.Ph.D@UNIPG- Sviluppo dell'Internazionalizazione del dottorato di ricerca: Sostegno della Fondazione Cassa di Risparmio di Perugia ai corsi internazionali di Dottorato UNIPG".

Conflicts of Interest: The authors declare no conflict of interest.

\section{References}

1. Mehmood, M.A.; Ibrahim, M.; Rashid, U.; Nawaz, M.; Ali, S.; Hussain, A.; Gull, M. Biomass production for bioenergy using marginal lands. Sustain. Prod. Consum. 2017, 9, 3-21. [CrossRef]

2. Bureau, J.C.; Swinnen, J. EU policies and global food security. Glob. Food Secur. 2018, 16, 106-115. [CrossRef]

3. McKendry, P. Energy production from biomass (part 1): Overview of biomass. Bioresour. Technol. 2002, 83, 37-46. [CrossRef]

4. Turco, R.; Tesser, R.; Cucciolito, M.E.; Fagnano, M.; Ottaiano, L.; Mallardo, S.; Malinconico, M.; Santagata, G.; Di Serio, M. Cynara cardunculus Biomass Recovery: An Eco-Sustainable, Nonedible Resource of Vegetable Oil for the Production of Poly(lactic acid) Bioplasticizers. ACS Sustain. Chem. Eng. 2019, 7, 4069-4077. [CrossRef]

5. Gominho, J.; Curt, M.D.; Lourenço, A.; Fernández, J.; Pereira, H. Cynara cardunculus L. as a biomass and multi-purpose crop: A review of 30 years of research. Biomass Bioenergy 2018, 109, 257-275. [CrossRef] 
6. Ottaiano, L.; Di Mola, I.; Impagliazzo, A.; Cozzolino, E.; Masucci, F.; Mori, M.; Fagnano, M. Yields and quality of biomasses and grain in Cynara cardunculus L. grown in southern Italy, as affected by genotype and environmental conditions. Ital. J. Agron. 2017, 12, 375-382. [CrossRef]

7. Archontoulis, S.V.; Struik, P.C.; Vos, J.; Danalatos, N.G. Phenological growth stages of Cynara cardunculus: Codification and description according to the BBCH scale. Ann. Appl. Biol. 2010, 156, 253-270. [CrossRef]

8. Bolohan, C.; Marin, D.I.; Mihalache, M.; Ilie, L.; Oprea, C. Research on Cynara cardunculus L. Species under the conditions of southeastern romania area. Agronomy 2013, 56, 429-432.

9. Fernández, J.; Curt, M.D.; Aguado, P.L. Industrial applications of Cynara cardunculus L. for energy and other uses. Ind. Crop. Prod. 2006, 24, 222-229. [CrossRef]

10. Raccuia, S.A.; Melilli, M.G. Biomass and grain oil yields in Cynara cardunculus L. genotypes grown in a Mediterranean environment. Field Crop. Res. 2007, 101, 187-197. [CrossRef]

11. Ierna, A.; Mauromicale, G. Cynara cardunculus L. genotypes as a crop for energy purposes in a Mediterranean environment. Biomass Bioenergy 2010, 34, 754-760. [CrossRef]

12. Angelini, L.G.; Ceccarini, L.; Nassi o Di Nasso, N.; Bonari, E. Long-term evaluation of biomass production and quality of two cardoon (Cynara cardunculus L.) cultivars for energy use. Biomass Bioenergy 2009, 33, 810-816. [CrossRef]

13. Fernández, J.; Hidalgo, M.; Del Mont, J.P.; Curt, M.D. Cynara cardunculus L. as a perennial crop for non-irrigated lands: Yields and applications. Acta Hortic. 2005, 681, 109-116. [CrossRef]

14. Gil, M.; Arauzo, I.; Teruel, E.; Bartolomé, C. Milling and handling Cynara cardunculus L. for use as solid biofuel: Experimental tests. Biomass Bioenergy 2012, 41, 145-156. [CrossRef]

15. Cavalaglio, G.; Petrozzi, A.; Coccia, V.; D’Antonio, S.; Cotana, S. Mass and Energy Flows of Cardoon Oil in a Prototype System for Seeds Milling and Vegetable Oil Treatment and Cogeneration. Energy Procedia 2015, 82, 681-686. [CrossRef]

16. Coulson, M.; Bridgewater, A.V. Fast Pyrolysis of annually harvested crops for bioenergy applications. In Proceedings of the 2nd World Conference on Biomass, Rome, Italy, 10-14 May 2004; p. 1098.

17. Curt, M.D.; Sánchez, G.; Fernández, J. The potential of Cynara cardunculus L. for seed oil production in a perennial cultivation system. Biomass Bioenergy 2002, 23, 33-46. [CrossRef]

18. Baskar, G.; Kalavathy, G.; Aiswarya, R.; Selvakumari, I.A. Advances in bio-oil extraction from nonedible oil seeds and algal biomass. In Advances in Eco-Fuels for a Sustainable Environment; Woodhead Publishing Series in Energy: Cambridge, UK, 2019; pp. 187-210.

19. Petropoulos, S.A.; Fernandes, Â.; Calhelha, R.C.; Danalatos, N.; Barros, L.; Ferreira, I.C.F.R. How extraction method affects yield, fatty acids composition and bioactive properties of cardoon seed oil? Ind. Crop. Prod. 2018, 124, 459-465. [CrossRef]

20. Azadmard-Damirchi, S.; Habibi-Nodeh, F.; Hesari, J.; Nemati, M.; Achachlouei, B.F. Effect of pretreatment with microwaves on oxidative stability and nutraceuticals content of oil from rapeseed. Food Chem. 2010, 121, 1211-1215. [CrossRef]

21. Erna, S.; Robert, M.; Hero, J.H.; Antonius, A.B. Optimization of mechanical oil extraction from Jatropha curcas L. kernel using response surface method. Ind. Crop. Prod. 2015, 63, 294-302.

22. Elhassan, S.H.A.R. Mechanical Expression of Oil from Sesame (Sesamum indicum L.). Ph.D. Thesis, University of Khartoum, Khartoum, Sudan, 2009.

23. Nde, D.; Foncha, A.C. Optimization Methods for the Extraction of Vegetable Oils: A Review. Processes 2020, 8, 209. [CrossRef]

24. Bhuiya, M.M.K.; Rasul, M.G.; Khan, M.M.K.; Ashwath, N.; Azad, A.K.; Mofijur, M. Optimisation of Oil Extraction Process from Australian Native Beauty Leaf Seed (Calophyllum inophyllum). Energy Procedia 2015, 75, 56-61. [CrossRef]

25. Guédé, S.S.; Soro, Y.R.; Kouamé, A.F.; Brou, K. Optimization of screw press extraction of Citrillus lanatus seed oil and physicochemical characterization. Eur. J. Food Sci. Technol. 2017, 5, 35-46.

26. Fagnano, M.; Boccia, L.; Pindozzi, S.; Infascelli, R.; Faugno, S. Aree potenzialmente convertibili a colture energetiche: Caso studio della regione campania. In Proceedings of the XLI Convegno Societa Italiana di Agronomia, Bari, Italy, 19-21 September 2012; Società Italiana di Agronomia: Bari, Italy; pp. 464-466.

27. Mettler Toledo Instruments-Moisture Analyzer HB43-S. Available online: https://www.mt.com/dam/P5/ labtec/05_Moisture_Analyzer/02_Advanced_Line/03_Documents/03_Operating_Instructions/HB43-S_OI_ en.pdf (accessed on 5 November 2020). 
28. Sluiter, A.; Ruiz, R.; Scarlata, C.; Sluiter, J.; Templeton, D. Determination of Extractives in Biomass: Laboratory Analytical Procedure; Technical Report. 510-42619; National Renewable Energy Laboratory: Golden, CO, USA, 2008.

29. LECO Instruments-Calorimeter AC-350. Available online: http://www.leco.co.kr/pdf/Organic/ac350(-012) .pdf (accessed on 5 November 2020).

30. Mancini, M.; Volpe, M.L.; Gatti, B.; Malik, Y.; Moreno, A.C.; Leskovar, D.; Cravero, V. Characterization of cardoon accessions as feedstock for biodiesel production. Fuel 2019, 235, 1287-1293. [CrossRef]

31. Mehta, P.S.; Anand, K. Estimation of a Lower Heating Value of Vegetable Oil and Biodiesel Fuel. Energy Fuels 2009, 23, 3893-3898. [CrossRef]

32. Genovese, C.; Platania, C.; Venticinque, M.; Calderaro, P.; Argento, S.; Scandurra, S.; Raccuia, S.A. Evaluation of cardoon seeds presscake for animal feeding. Acta Hortic. 2016, 1147, 323-328. [CrossRef]

Publisher's Note: MDPI stays neutral with regard to jurisdictional claims in published maps and institutional affiliations.

(C) 2020 by the authors. Licensee MDPI, Basel, Switzerland. This article is an open access article distributed under the terms and conditions of the Creative Commons Attribution (CC BY) license (http://creativecommons.org/licenses/by/4.0/). 